\title{
A difusão lexical num fenômeno de aspiração do português
}

\author{
Mônica Auler \\ Universidade Federal do Rio de Janeiro
}

\section{Abstract}

The phonetic/phonological aspects involved in the pronunciation of the post-vocalic $s$ have already been analysed in several works concerning different dialects of Brazilian Portuguese. This paper presents a study of some lexical factors involved in the aspiration of the post-vocalic $s$ in the dialect of Rio de Janeiro as an alternative approach to the phenomenon. It also reinforces the applicability of the Lexical Diffusion model to Portuguese. 


\section{INTRODUÇÃO}

pronúncia do s pós-vocálico já foi objeto de estudo na fala de Natal (RN),
de Fortaleza (CE) e de Cordeiro (RJ) (cf. Pessoa, 1986; Roncarati, 1988;
e Gryner \& Macedo, 1981) vista sob o prisma fonético/fonológico. Neste
sentido foi constatado um processo de enfraquecimento envolvendo as
quatro pronúncias possíveis do s travador de sílaba: alveolar > palatal > aspirada > zero. Com o intuito de verificar a existência desse processo de enfraquecimento no município do Rio de Janeiro, Scherre e Macedo (cf. Scherre \& Macedo, 1989) analisaram os dados de 18 informantes e, ao invés do esperado enfraquecimento, constataram um reforço da pronúncia palatal. Além disso, o tipo de item léxico foi selecionado pelo programa computacional como o fator mais influente na realização do s pós-vocálico.

Este trabalho tem como objetivo analisar parâmetros do léxico e avaliar a possibilidade de atuação da hipótese da difusão lexical no fenômeno de aspiração do $s$ pós-vocálico, numa pequena amostra do português falado no município do Rio de Janeiro.

A hipótese da difusão lexical postula que as mudanças se implementam na língua gradualmente através de determinados itens do léxico. É imprescindivel, portanto, para os estudos nessa área, o confronto do comportamento variável em estágios sincrônicos diferentes. Nesse trabalho, serão analisados apenas fatores de ordem lexical, numa perspectiva diacrônica. Os dados foram retirados de entrevistas envolvendo os mesmos falantes em dois estágios temporais distintos. Embora o intervalo entre os dois estágios de tempo seja pequeno ( 6 anos), é possível que se extraiam dessa análise tesultados preliminares sobre a atuação de fatores lexicais nesse fenômeno. Espera-se também que a análise em tempo real apresente dados relevantes que permitam inferir se a aspiração do s pós-vocálico está em progresso ou em variação estável.

\section{PARÂMETROS LEXICAIS NA ATUAÇÃO DA ASPIRAÇÃO}

Os dados deste trabalho provêm de 20 entrevistas realizadas em dois tempos isolados (1982 e 1988), com 10 informantes residentes na cidade do Rio de Janeiro. Os corpora obtidos correspondem a todas as ocorrências de $\mathrm{s}$ pós-vocálico e de seus homófonos, representados por $\mathbf{x}$ e $\mathbf{z}$ na lingua escrita, tal como em 'experiência' e 'rapaz'. Foram excluídos morfemas de plural, casos de contexto dissimulador (/nつyštãmus/ para 'nós estamos') e casos cuja percepção era duvidosa. O corpus do primeiro tempo totalizou 1035 dados e o do segundo, 1021. 
Inicialmente foram controladas as quatro pronúncias possiveis do $\mathrm{s}$ pós-vocálico (alveolar, palatal, aspirada e zero), a fim de se confrontar a proporção da realização aspirada nos corpora com cada uma das outras realizações.

O quadro geral da distribuição dessas quatro pronúncias (Tab. 1) confirma a expectativa de uma maior incidência da pronúncia palatal, seguida pela alveolar e, em escala bem menor, pelas pronúncias aspirada e zero. As percentagens globais da pronúncia aspirada nos dois tempos indicam uma variação estável.

TABELA 1

Distribuição das quatro pronúncias possíveis (alveolar, palatal, aspirada e zeto), em dois estágios.

\begin{tabular}{c|c|c|c|c}
\hline \multirow{2}{*}{ Estágio } & \multicolumn{4}{|c}{ Realização } \\
\cline { 2 - 5 } $1^{\circ}$ tempo & $\mathrm{A}$ & $\mathrm{P}$ & $\mathrm{X}$ & $\emptyset$ \\
\hline \multirow{2}{*}{$2^{\circ}$ tempo } & $\frac{260}{1035}$ & $\frac{652}{1035}$ & $\frac{66}{1035}$ & $\frac{57}{1035}$ \\
& $\frac{167}{1021}$ & $\frac{763}{1021}$ & $\frac{44}{1021}$ & $\frac{47}{1021}$ \\
& $16,4 \%$ & $74,7 \%$ & $4,3 \%$ & $4,6 \%$ \\
\hline
\end{tabular}

Dentre as variáveis controladas, a variável Categoria Gramatical mostrou-se a mais relevante. $O$ controle desta variável visava detectar se havia alguma classe de palavras mais suscetível ao fenômeno de aspiração do s pós-vocálico. Foram controladas 11 categorias, das quais só 6 apresentaram casos de aspiração: verbo (V); advérbio (D); conjunção (C); numeral (N); 'mesmo' (M) e adjetivo (A). A criação de uma categoria só para as ocorrências do vocábulo mesmo se justifica pela intuição de provável grande afetamento deste item. A não inclusão desta categoria implicaria a dispersão desse item em outras categorias, já que ele pode assumir diferentes classes gramaticais. 


\section{TABELA 2}

Incidência de aspiração em relação à Categoria Gramatical.

\begin{tabular}{c|c|c|c|c|c|c}
\hline \multirow{2}{*}{$\begin{array}{c}\text { categoria } \\
\text { gram. }\end{array}$} & \multicolumn{6}{|c|}{ estágio } \\
\hline \multirow{3}{*}{$1^{\text {Q }}$ tempo } & $\frac{5}{311}$ & $\frac{14}{137}$ & $\frac{14}{121}$ & $\frac{11}{100}$ & $\frac{22}{50}$ & $\frac{0}{40}$ \\
& $1,6 \%$ & $10,2 \%$ & $11,6 \%$ & $11 \%$ & $44 \%$ & $0 \%$ \\
\hline \multirow{2}{*}{$2^{2}$ tempo } & $\frac{2}{291}$ & $\frac{8}{115}$ & $\frac{8}{76}$ & $\frac{4}{134}$ & $\frac{21}{49}$ & $\frac{1}{44}$ \\
& $0,7 \%$ & $7 \%$ & $10,5 \%$ & $3 \%$ & $42,9 \%$ & $2,3 \%$ \\
\hline
\end{tabular}

A categoria que isola as ocorrências de mesmo (Tab. 2) apresenta comportamento bastante diferenciado das demais. $O$ alto índice de aspiração no elemento mesmo, face a todas as outras categorias, vem ao encontro da hipótese de que o fenômeno pode estar lexicalmente condicionado. Em consequiência dessa primeira evidência, foram refeitas as estatísticas da realização global da aspiração, excluindo-se as ocorrências de mesmo. Houve uma pequena queda, considerada irrelevante: no primeiro tempo, a aspiração global cai para $3,9 \%$ e no segundo, para $2,4 \%$.

Outra variável controlada foi a posição do $s$ pós-vocálico no interior da palavra (posição medial ou final). As estatísticas englobando todo o léxico afetado pela aspiração não são significativas (Tab. 3). Entretanto, retirando-se as ocorrências de mesmo, a aspiração fica quase totalmente restrita à posição final: o afetamento em posição medial cai para $0,2 \%$, no primeito tempo, e $0 \%$, no segundo. Esses dados indicam que, exceto pelas ocorrências no vocábulo mesmo, a aspiração é um fenômeno exclusivo da posição final de palavra.

TABELA 3

Incidência de aspiração em relação à Posição.

\begin{tabular}{l|c|c}
\hline \multirow{2}{*}{ Estágio } & \multicolumn{2}{|c}{ Posição } \\
\cline { 2 - 3 } & $\mathrm{M}$ & $\mathrm{F}$ \\
\hline \multirow{2}{*}{$1^{\mathrm{\rho}}$ tempo } & $\frac{23}{433}$ & $\frac{43}{602}$ \\
& $5,3 \%$ & $7,1 \%$ \\
\hline \multirow{2}{*}{$2^{\circ}$ tempo } & $\frac{21}{542}$ & $\frac{23}{479}$ \\
& $3,9 \%$ & $4,8 \%$ \\
\hline
\end{tabular}


A variável Par Mínimo foi controlada a fim de se avaliar a influência da carga funcional na aplicação da pronúncia aspirada, visto ser um pressuposto teórico corrente que itens morfêmicos que acumulam mudança de sentido são mais resistentes à mudança.

$\mathrm{Na}$ Tab. 4, verifica-se a predominância de aplicação do fenômeno na parte do léxico cuja forma aspirada constitui par mínimo com a equivalente não aspirada, fato contraditório com as expectativas iniciais de que a variação deveria incidir mais sobre os itens que não apresentassem mudança de significado. Isso pode ser explicado pelo fato de os pares mínimos assinalados só o serem no nível fonológico, isto é, pares como dez/der ou mas/mar são mínimos no nível fonológico, mas não o são no nível sintático.

TABELA 4

Incidência de aspiração em relação à carga funcional (Par Mínimo).

\begin{tabular}{l|c|c}
\hline \multirow{2}{*}{ Estágio } & \multicolumn{2}{|c}{ Parminimo } \\
\cline { 2 - 3 } & $\frac{18}{155}$ & $\frac{48}{880}$ \\
\hline \multirow{2}{*}{$1^{2}$ tempo } & $11,6 \%$ & $5,5 \%$ \\
\hline \multirow{2}{*}{$2^{2}$ tempo } & $\frac{9}{102}$ & $\frac{40}{919}$ \\
& $8,8 \%$ & $4,4 \%$ \\
\hline
\end{tabular}

A última variável controlada foi Morfema (prefixo, radical e sufixo). Nesta variável a aplicação foi praticamente categórica no radical, ocorrendo apenas uma vez a aspiração no sufixo, no primeiro tempo.

$\mathrm{Na}$ análise das percentagens individuais da realização aspirada vista em dois tempos (Tab. 5), os fatos mais relevantes são: o desaparecimento total da aspiração em dois informantes, no segundo tempo (MAR e FAT), o quase desaparecimento num terceiro (SAN) e a queda bastante acentuada no informante PRO. Dois informantes apresentam comportamento bem equilibrado (NAD e GLO), outros diminuíram a incidência de aspiração em proporção pouco significativa (JAN, ROB e AGO) e apenas um informante aumentou significativamente a pronúncia aspirada (VAS). 
TABELA 5

Incidência individual de aspiração.

\begin{tabular}{|c|c|c|}
\hline \multirow[b]{2}{*}{ Informantes } & \multicolumn{2}{|c|}{ Realização } \\
\hline & $\underset{19}{X}$ & $\begin{array}{c}X \\
2^{2} \text { tempo }\end{array}$ \\
\hline \multirow[t]{2}{*}{ JAN } & $\frac{7}{116}$ & $\frac{6}{182}$ \\
\hline & $6 \%$ & $3,3 \%$ \\
\hline \multirow[t]{2}{*}{ ROB } & $\frac{16}{80}$ & $\begin{array}{r}6 \\
41\end{array}$ \\
\hline & $20 \%$ & $14,6 \%$ \\
\hline \multirow[t]{2}{*}{ MAR } & $\begin{array}{r}5 \\
91\end{array}$ & $\frac{0}{44}$ \\
\hline & $5,5 \%$ & $0 \%$ \\
\hline \multirow[t]{2}{*}{ FAT } & $\begin{array}{r}2 \\
114\end{array}$ & $\begin{array}{r}0 \\
122\end{array}$ \\
\hline & $1,8 \%$ & $0 \%$ \\
\hline \multirow[t]{2}{*}{ VAS } & $\begin{array}{r}6 \\
122\end{array}$ & $\begin{array}{r}11 \\
130\end{array}$ \\
\hline & $4,9 \%$ & $8,5 \%$ \\
\hline \multirow[t]{2}{*}{ AGO } & $\begin{array}{r}7 \\
103\end{array}$ & $\frac{3}{75}$ \\
\hline & $6,8 \%$ & $4 \%$ \\
\hline \multirow[t]{2}{*}{ NAD } & $\begin{array}{r}7 \\
69\end{array}$ & $\begin{array}{r}8 \\
72\end{array}$ \\
\hline & $10,1 \%$ & $11,1 \%$ \\
\hline \multirow[t]{2}{*}{ SAN } & $\begin{array}{r}4 \\
129\end{array}$ & $\frac{1}{102}$ \\
\hline & $3,1 \%$ & $1 \%$ \\
\hline \multirow[t]{2}{*}{ PRO } & $\begin{array}{r}7 \\
74\end{array}$ & $\frac{1}{36}$ \\
\hline & $9,5 \%$ & $2,8 \%$ \\
\hline \multirow[t]{2}{*}{ GLO } & $\begin{array}{r}5 \\
137\end{array}$ & $\begin{array}{r}8 \\
217\end{array}$ \\
\hline & $3,6 \%$ & $3,7 \%$ \\
\hline
\end{tabular}


Ao isolar o grupo de quatro informantes que apresentaram nenhuma ou baixa incidência de aspiração no segundo tempo, fica ainda mais evidente a perda da pronúncia aspirada (Tab. 6).

\section{TABELA 6}

lincidência de aspiração num grupo de quatro informantes

(MAR, FAT, SAN e PRO).

\begin{tabular}{c|c}
\hline \multirow{2}{*}{ Estágio } & Realização \\
\cline { 2 - 2 } & $\mathrm{X}$ \\
\hline \multirow{2}{*}{$1^{2}$ tempo } & $\frac{18}{408}$ \\
& $\frac{4,4 \%}{2}$ \\
\hline $2^{\circ}$ tempo & $\frac{304}{}$ \\
\hline
\end{tabular}

Tudo leva a crer que há fatores sociais que explicam o fato de esses quatro informantes terem eliminado ou quase eliminado a pronúncia aspirada do s pós-vocálico de suas falas. $O$ fator mais forte deve ser a escolarização (Tab. 7). Todos os informantes desse grupo aumentaram o seu grau de instrução. Três deles chegaram, pelo menos, a ingressar no $3^{\circ}$ grau e outro apenas concluiu o $2^{\circ}$ grau, porém fez cursos de extensão e participou de congressos promovidos por universidades.

TABELA 7

Escolarização

\begin{tabular}{|c|c|c|}
\hline \multirow{2}{*}{ Informante } & \multicolumn{2}{|c|}{ Estágio } \\
\hline & $1^{2}$ tempo & $2^{2}$ tempo \\
\hline JAN & $4^{\mathrm{a}}$ & $4^{a}$ \\
\hline ROB & $4^{a}$ & $8^{9}$ \\
\hline MAR & $2^{9} \mathrm{col}$ & univ. \\
\hline FAT & $8^{\underline{a}}$ & $3^{\circ} \mathrm{col}$. \\
\hline VAS & $8^{a}$ & $8^{0}$ \\
\hline $\mathrm{AGO}$ & $5^{a}$ & $5^{\mathrm{o}}$ \\
\hline NAD & $7^{a}$ & $7^{2}$ \\
\hline SAN & $1^{2} \mathrm{col}$. & univ. \\
\hline PRO & $3^{2}$ col. & univ. \\
\hline GLO & $3^{2} \mathrm{col}$. & $3^{\circ} \mathrm{col}$ \\
\hline
\end{tabular}


Outro dado interessante é o fato de esses quatro informantes terem ingressado no mercado de trabalho, ao passo que na ocasião da primeira entrevista eram apenas estudantes. Pode ser que a entrada no mercado de trabalho, somada ao nível de escolarização alcançado, tenha representado uma maior exigência social por um melhor desempenho lingüistico.

$\mathrm{Na}$ análise do comportamento individualizado dos informantes, a Categoria Gramatical apresentou um dado relevante: no segundo tempo, dois informantes (ROB e NAD) aspiraram todas as emissões do item mesmo, sendo que ROB já apresentava um alto índice de aspiração nesse item ( $90 \%)$, no primeiro tempo. Esse dado corrobora a hipótese de que se há uma mudança, ela pode estar se implementando na língua através desse item lexical. Nos demais informantes não foi possível assinalar tendência de fortalecimento ou enfraquecimento de aspiração de mesmo ou de quaisquer das outras categorias devido à escassez de dados. Vale lembrar que a ocorrência ou não de um dado item lexical está ligada ao foco temático pelo qual a entrevista é direcionada. Nesse aspecto, as entrevistas do segundo estágio são muito diferentes das anteriores, porque praticamente só se limitam à coleta de dados sociais do informante, ao passo que nas entrevistas do primeiro estágio os informantes discorriam livremente sobre qualquer assunto que lhes dissesse respeito.

Através da elaboração de glossários, foram detectados todos os itens afetados pela aspiração em cada estágio. No primeiro estágio, a aspiração afetou 16 itens diferentes, dos quais apenas $\mathbf{8}$ foram afetados no segundo estágio: depois, dez, faz, mas, mais, mesmo, seis e três. A fim de testar a influência do grau de freqüência de um item no seu afetamento pela aspiração, foi organizada uma tabela que relaciona a freqüência de um item com o afetamento. Trabalhando somente com os 8 itens recorrentes nos dois estágios, foram estipulados, arbitrariamente, três graus de frequiência: baixa (até 20 ocortências), média (de 21 a 40 ocorrências) e alta (mais de 40 ocorrências). Os resultados numéricos estão na Tab. 8.

TABELA 8

Incidência de aspiração em relação à Freqüência.

\begin{tabular}{c|c|c|c}
\hline \multirow{2}{*}{ Estágio } & \multicolumn{3}{|c}{ Freqüência } \\
\cline { 2 - 4 } & baixa & média & alta \\
\hline \multirow{2}{*}{$1^{\circ}$ tempo } & $\frac{5}{31}$ & $\frac{5}{88}$ & $\frac{44}{267}$ \\
& $16,1 \%$ & $5,7 \%$ & $16,5 \%$ \\
\hline \multirow{2}{*}{$2^{\circ}$ tempo } & $\frac{3}{36}$ & $\frac{2}{72}$ & $\frac{34}{200}$ \\
& $8,3 \%$ & $2,8 \%$ & $17 \%$ \\
\hline
\end{tabular}

Nota-se que os itens de freqüência alta mantiveram na mesma média a tendência à aspiração nos dois estágios, mas os de freqüência baixa apresentaram comportamento bem diferente. Vale lembrar que Phillips (1984) postulou que a inovação deve afetar 
itens menos freqüentes quando envolve condicionamentos não-fisiológicos, processos mais sutis, portanto, como condicionamentos sócio-geográficos. Se a aspiração em itens de baixa freqüência está sendo aqui determinada por fatores de ordem social e/ou geográfica, é possível que este condicionamento ainda não esteja de todo fixado, daí a variação na incidência de aspiração nos dois tempos.

\section{CONSIDERAÇÕES FINAIS}

Os índices globais de aspiração do $\mathbf{s}$ pós-vocálico em dois estágios temporais distintos $(6,4 \%$ e $4,3 \%$, cf. Tab. 1) sugerem uma variação estável. Além disso, constatou-se pelo levantamento lexical que esta variação está localizada em poucos itens, sugerindo a atuação da difusão lexical. Contudo, não é descartada a influência de fatores fonéticos/fonológicos atestados em trabalhos anteriores. $O$ confronto de fatores lexicais e fonéticos/fonológicos na atuação desse fenômeno fica aqui como proposta para um futuro trabalho.

É possível que of fenômeno aqui tratado seja um indicador social de uma fala menos comprometida com a norma culta, dado o que foi visto na análise da evolução individual do fenômeno. Quer dizer, a aspiração não é um marcador dialetal diatópico, mas indicador de uma fala mais relaxada, despreocupada com a norma culta, própria de indivíduos que não estão sujeitos a pressões sociais sobre o seu desempenho lingüístico.

\section{REFERÊNCIAS BIBLIOGRÁFICAS}

GRYNER, H., MACEDO, A. T. La prononciation du s post-vocalique: deux processus de changement linguistique en portugais. In: Variation omnibus. Canadá: Linguistic Research, p.135-140, 1981.

PESSOA, M.A.F.C. Um processo de enfraquecimento na fonologia do português. Monografia apresentada no curso de Doutorado em Lingüística da Faculdade de Letras da UFRJ, 1986.

PHILLIPS, B.S. Word frequency and the actuation of sound change. Language, v.60, n.2, p.320-342, junho, 1984.

RONCARATI, C.N.S. Enfraquecimento das fricativas sonoras. In: Relatório final à FINEP - Projeto Dialetos Sociais Cearenses. Fortaleza: Universidade Federal do Ceará, 1988. (Convênio FINEP/CCPC 41.85.0655.00).

SCHERRE, M.M.P., MACEDO, A.T. Variação e mudança: o caso da pronúncia do S pós-vocálico. In: Relatório final à FINEP - Projeto Mecanismos Funcionais do Uso Lingüistico. Rio de Janeiro: Universidade Federal do Rio de Janeiro, 1989. (Convênio FINEP/UFRJ, mimeogr.). 